\title{
Exclusão digital, diferenças no acesso e uso de tecnologias de informação e comunicação: questões conceituais, metodológicas e empíricas. ${ }^{1}$
}

\author{
Digital exclusion, differences in access and use of \\ information and communication technologies: \\ conceptual, methodological and empirical \\ questions
}

Marcelo Ferreira Trezza Knop*1

Palavras-chave: Desigualdade social; Desiguadade categórica;

Exclusão digital.
Resumo: Este artigo destaca as relações desiguais entre educação e trabalho, desencadeadas por distintos acessos aos denominados bens generativos de valor; nesse caso, as tecnologias de informação e comunicação. Dessa forma, como principais resultados alcançados, destaca-se que a exclusão/inclusão digital é um fenômeno complexo e multifacetado, ou seja, que vai muito além que disponibilizar computadores com acesso à internet a determinados atores sociais. Essas diferenças de oportunidades estão relacionadas a diversos fatores, tais como, a falta de infraestrutura física e de TIC adequada, ou seja, laboratório com hardwares, softwares e periféricos em perfeito funcionamento e atualizados, como também a conexão ou banda de internet (mostrando que a disponibilização desses meios, por si só, não diminuiu esse distanciamento). Relaciona-se também a impossibilidade de acesso e uso contínuo das tecnologias de informação e, consequentemente, das ferramentas aprendidas nos encontros (pois, não há o desejo das instituições pesquisadas em ampliar esse acesso e incluí-los no dia-a-dia dos alunos); aos tipos de usos das tecnologias de informação pelos beneficiários do projeto, nas horas de aula e fora dela (principalmente o grande interesse pelas redes 


\author{
Keywords: \\ Social inequality; \\ Categorical inequality; \\ Digital exclusion.
}

sociais virtuais e por jogos); e aos diferentes níveis de aprendizado verificados durante os cursos, com destaque para tipos diferenciados de interesse (mesmo por jovens pertencentes ao mesmo grupo social).

\begin{abstract}
This article highlights the unequal relationship between education and work, triggered by different accesses to so-called generative value goods; in this case, information and communication technologies. Thus, as main results achieved, it's emphasized that digital exclusion/inclusion is a complex and multifaceted phenomenon, that is, that goes much further than providing computers with internet access to certain social actors. These differences in opportunities are related to a number of factors, such as the lack of physical infrastructure and adequate ICT, that is, a laboratory with hardware, software and peripherals in perfect working order and updated, as well as the internet connection or bandwidth (showing that the availability of these means alone did not diminish this distance). It is also related to the impossibility of access and continuous use of the information technologies and, consequently, of the tools learned in the meetings (therefore, there is not the desire of the studied institutions to extend this access and to include them in the day-to-day of the students); the types of uses of information technologies by project beneficiaries, during and after school hours (mainly the great interest in virtual social networks and games); and different levels of learning during the courses, with special emphasis on differentiated types of interest (even by young people belonging to the same social group).
\end{abstract}

\title{
Introdução
}

$\mathrm{O}$ estudo da desigualdade enfatiza, dentre as diversas outras relações advindas, que educação e trabalho estão intimamente interligadas, a partir de instituições, práticas, regularidades e comportamentos, que são acessados de formal desigual por distintas categorias da sociedade (BILLS, 2004). Ou seja, oportunidades e não-oportunidades, ligadas à obtenção e posse de determinadas credenciais, auxiliam a classificar pessoas em relação a estruturas hierárquicas de trabalho, locais de trabalho e carreiras, posicionando as mesmas na sociedade (BROWN, 2001). Isso não se torna diferente quando se fala das tecnologias de informação e comunicação, pois o tema exclusão digital tem sido destacado em discussões diversas, sendo sua íntegra a questão da distribuição desigual de recursos, acesso, compreensão e uso no que se refere a tais tecnologias. 
Esse assunto tem se tornado um importante foco de extensão e pesquisa, pois, envolve mais do que simplesmente documentar as características das pessoas que possuem ou não computadores; mas, também, o acesso ou não a essas tecnologias, seja em casa, no trabalho e ou na escola, além do o uso contínuo (ou descontínuo) dessas ferramentas, que se soma às características dos agentes envolvidos e às estruturas sociais que dão suporte ou não a esse processo. Isso porque, pode-se seguramente afirmar que as conceituadas novas tecnologias de informação e comunicação se tornaram a espinha dorsal da modernidade, pois, acessar, compreender e utilizar estas ferramentas e seus conteúdos informacionais de forma eficaz é a chave para o desenvolvimento de indivíduos e comunidades.

Esses ativos produtores de valor (ou generativos de valor) são recursos cujo controle permitem aumentar o valor de bens e serviços, considerando que nas relações de propriedade há uma distribuição assimétrica destes ativos, gerando reservas de oportunidades e, consequentemente, as classes sociais (WRIGHT, 1969; TILLY, 1999).

Neste aspecto, a situação se agrava, pois, desigualdades econômicas, sociais, culturais e de status se reproduzem na dimensão virtual e tecnológica, o que significa restrição de acesso a indivíduos já marginalizados, reificando assim suas condições de vida e trabalho. É a chamada exclusão digital, ou seja, a diferença entre os indivíduos e as sociedades que têm os recursos para participar na era da informação e aqueles que não o fazem; sendo que, no que tange a sua análise e interpretação, verifica-se algo mais complexo do que oferecer computador e acesso à internet a indivíduos (CHEN e WELLMAN, 2005).

Visando contribuir para a discussão e aprofundamento do tema e para o desenvolvimento em nível local é que este artigo se estrutura, em nítida integração entre pesquisa e extensão. Assim, este apresenta como problema de pesquisa a seguinte questão: jovens, pertencentes a grupos sociais com nenhum ou pouco acesso e uso às tecnologias de informação e comunicação, podem ser habilitados, a partir de projetos de curta duração, para obter os recursos necessários a fim de serem considerados incluídos digitalmente?

Consequentemente, este artigo apresenta como objetivo geral compreender quais são os desafios da inclusão digital de jovens frequentadores de duas entidades do bem-estar do menor no Estado de Minas Gerais. Especificamente, objetiva-se: analisar como fatores de acesso social (econômicos e culturais) e de infraestrutura de tecnologia de informação que dificultam a inclusão digital; identificar comportamentos distintos dos beneficiários do projeto em relação aos fatores de uso das tecnologias de informação e comunicação - interesse, habilidades e tipos de uso (especificamente, como usa); propor, a partir dos dados coletados e do referencial teórico utilizado, conceitos e metodologias que abordem o tema de forma mais ampla e complexa.

Para responder o problema de pesquisa e alcançar os objetivos propostos utilizou-se, como referencial teórico, temáticas relacionadas a desigualdade categórica e à exclusão digital. E, visando aglutinar teoria e prática, no capítulo

Caderno Eletrônico de Ciências Sociais, Vitória, v. 5, n. 2, pp. 39-58, 2017. 
de metodologia, recorre-se aos métodos de pesquisa-ação e análise de conteúdo, para coleta e análise de dados, respectivamente.

\section{Referencial Teórico}

\section{Desigualdade Categórica}

A desigualdade social ocorre quando os atores sociais são estratificados em grupos distintos com base nas diferenças individuais ou características socialmente definidas. Estas categorias, socialmente definidas como formas de estratificação, afetam o acesso a recursos como a riqueza, o poder, o prestígio, a educação e a saúde, bem como o acesso e o uso das tecnologias disponíveis. Para isso, deve-se reconhecer a exploração e a dominação como eixos centrais da análise de classe, destacando as estruturas de posições sociais distintas que as pessoas ocupam (WRIGHT, 2008). Ou seja, grupos de status excluem os outsiders do acesso e uso de certos recursos valiosos, a partir de deveres, direitos e privilégios; gerando retornos desproporcionais, que são canalizados para aqueles que ocupam posições estratégicas nessas redes, visando a conquista de estima e respeito (ERICKSON, 1997; TILLY, 1999; RIDGEWAY, 2013). A estratificação, portanto, aloca pessoas para categorias sociais e institucionaliza práticas que dispõem recursos desiguais através destas categorias. Esses recursos podem ser materiais, tais como renda e riqueza; podem ser simbólicos, como prestígio e posição social; ou podem ser emocionais, tais como amor e carinho. Portanto, os sistemas de estratificação ordenam as pessoas verticalmente em uma estrutura social caracterizada por uma parte superior e uma inferior distintas (MASSEY, 2007); sendo produzidos através do tempo e entre gerações (TILLY, 1998). Essas características podem ser delimitadas sob o termo "desigualdade categórica", quando se referem às vantagens sistemáticas adquiridas por determinados grupos, com base em categorias ou pares de categorias - "a desigualdade consiste em uma distribuição desigual de atributos entre unidades sociais como indivíduos, categorias, grupos ou regiões" (TILLY, 1998, p. 25). Nesse sentido, as elaborações sociais de categorias objetivam a criação de fronteiras e barreiras que limitam a um determinado grupo a disposição de um recurso valioso e o usufruto de oportunidades e recompensas desproporcionais, gerando um mecanismo de classificação injusto e destrutivo, qual seja, a desigualdade. Ou seja, os sistemas de classificação não evoluem naturalmente, pois "pairam" sobre uma extensa estrutura social de diferenças que não variam continuamente (de indivíduo para indivíduo), mas em um "cacho" categórico por gênero, nacionalidade, etnia, classe, acesso à informação, etc. Essas posições estão ligadas a recompensas, que, por sua vez, conectam-se com mecanismos de classificação e características pessoais (TILLY, 1999; 2005; MASSEY, 2007).

Ou seja, a desigualdade contemporânea deriva-se, de acordo com THERBORN (2006), de quatro formas básicas, quais sejam: primeiramente, através do distanciamento que se dá pelo processo competitivo instituído pelo capitalismo atual, abrangendo concepções liberais como mérito e credenciais, 
principalmente no que diz respeito às ligações entre escolaridade e local de trabalho; questões também levantadas inicialmente por COLLINS (1979) e, após, por BILLS (2004). Secundariamente, a desigualdade vem sendo produzida por meio de mecanismos de exclusão, a saber, barreiras que são erguidas para impedir o acesso a determinados recursos, que podem ser, segundo TILLY (1998), desenvolvidas através de vínculos fortes, médios e fracos, ou por meio de arranjos e pares categóricos que se combinam e acentuam esse processo de exclusão, tal como gênero com raça, raça com renda, renda com escolaridade, profissão com status, entre outros. Em terceiro lugar, as noções de hierarquização, onde as sociedades e as organizações relacionam-se por meio de escalas que se sobrepõem umas às outras, de acordo com o que se é alocado, como, por exemplo, recursos, riquezas e poder. Por fim, reforçando as análises marxistas, o autor argumenta que o quarto fator é a exploração, quando as riquezas derivam da subjugação dos pobres e desfavorecidos.

Portanto, esse trabalho terá como foco a relação entre educação e trabalho na consolidação da desigualdade social, a partir da concepção credencialista, que combina análise histórica e teórica, visando demonstrar a competição entre grupos de status como a causa primária da estratificação credencial nas profissões e no mercado de trabalho burocrático (COLINS, 1979; BILLS, 2004).

\section{Exclusão Digital}

$\mathrm{Na}$ modernidade, pode-se confirmar, seguramente, a presença da chamada era da comunicação, na qual a informática e as telecomunicações assumem um papel de relevância preponderante, contribuindo para embasar significativas transformações na sociedade. Sobre este aspecto, pode-se perceber que a convergência tecnológica, mensurada pela proximidade entre a informática e as telecomunicações, tende a impactar diretamente na vida das pessoas, sendo esse movimento tão avassalador que, repentinamente, passou a ser profuso e amplamente disponível, em condições genéricas.

Por outro lado, tem-se ampliado o caráter assimétrico e excludente do atual processo de globalização econômica, impondo novas pautas de comportamento e configurando novos mercados de consumo, ou seja, incidindo de forma diferenciada sobre os indivíduos e grupos, em uma sociedade já acentuadamente desigual como a brasileira (TESTA, 2007; MATOS e CHAGAS, 2008; FERNANDEZ, 2010). TILLY (2006), por sua vez, destaca que, a partir da segunda metade do século passado, as diferenças ligadas ao capital financeiro, à informação, aos meios de comunicação e ao conhecimento técnico-científico participaram, cada vez mais, na produção de desigualdade, especialmente no plano internacional. Já neste século, esses recursos se tornaram ainda mais importantes, tanto local como internacionalmente. É também neste sentido que CHEN E WELLMAN (2005) destacam a exclusão digital como um fenômeno social multidimensional, perpassada pelas desigualdades sociais em nível global, nacional, comunitário e do indivíduo. 
Essa diferenciação é devida, principalmente, à realidade histórica vivenciada em diversos países e no Brasil, onde determinantes da exclusão social estão presentes na exclusão digital (CYSNE, ALVES e CÔRTES, 2007; MATTOS E CHAGAS, 2008; YOUNG, 2008; WARSCHAUER, 2003; WILSON, WALLIN, REISER, 2003, GOODE, 2010; HARGITTAI, 2008). Ou seja, essa abundância de informações e novas tecnologias não têm o mesmo alcance para todos os grupos da sociedade.

Neste sentido, observa-se o surgimento de mais uma dimensão de segregação e separação entre pessoas e grupos, representada pelo nível de acesso, uso e domínio das ferramentas de informática ou não. Esse fenômeno tem sido conceituado por muitos autores como exclusão digital que, de acordo com TAKAHASHI (2005), é nova na forma, mas, muito antiga na causa.

Ou seja, a exclusão digital é a diferença entre aqueles que estão colhendo os benefícios de uso das novas tecnologias de informação e comunicação e aqueles que não (NTIA, 2004); alargando as lacunas entre ricos e pobres, dentro e entre países, mais especificamente entre jovens (LIVINGSTONE e HELSPER, 2007). Continuando sua linha de pensamento, LIVINGSTONE E HELSPER (2007, p. 685), afirmam em seu estudo que "jovens que usam a internet com mais frequência, tem mais oportunidades online"; e, inversamente, os que passaram a ter acesso mais recentemente, e que não têm confiança nas suas habilidades, usam a internet de forma mais conservadora, ocupando menos oportunidades.

PETER E VALKENBURG (2006) também compartilham da percepção acima. Isso porque, em um estudo que também envolve o uso da internet de forma desigual por adolescentes, os autores, a partir de análise multivariada, destacam que adolescentes com melhores níveis socioeconômicos e cognitivos usam a mesma, mais frequentemente, para buscar informações, e menos, para buscar entretenimento, em relação a seus pares menos favorecidos.

O que se percebe nestas pesquisas é que o estudo da exclusão digital é, muitas vezes, restrito quase exclusivamente ao acesso ou o não acesso à internet, como pode-se observar acima. É neste sentido que CHEN E WELLMAN (2005) e VEHOVAR et al. (2006) afirmam que esta visão reducionista das pesquisas sobre a divisão digital, a partir de uma visão bivariada (como variável principal o acesso ou não à internet), são ainda imprecisas, pois devem observar um conjunto de variáveis e correlações mais extenso (não descredenciando, de imediato, as diversas possibilidades). CHEN E WELLMAN (2005) ainda são mais enfáticos ao destacar que a divisão digital é um fenômeno multinível e multidimensional, afetada pela desigualdade social em níveis global, nacional, comunitária e individual, tornando a discussão e delimitação do tema ainda mais abrangente e complexa.

É neste sentido também que HARGITTAI (2010) enfatiza que, mesmo tendo acesso à rede, há uma diferença significativa no que tange ao uso da internet e a habilidade informacional, por influências de classe, educação parental, gênero, raça, etnia e localização geográfica. Busca-se, portanto, 
estudar a desigualdade digital categórica de forma mais abrangente e complexa, considerando questões de acesso social, ou seja, (fatores2 econômicos e culturais que afetam o igual acesso à internet, tendo a renda como um fator de relevância); fatores estruturais/institucionais de acesso (infraestrutura de TI do equipamento utilizado e "largura" de banda); e de uso de tais tecnologias (autonomia e habilidade de uso, habilidade e uso social3); neste caso, pertencente a determinado grupo (jovens frequentadoras/moradoras de entidades do bem-estar do menor).

Uma outra questão importante que se apresenta aqui, de imediato, está relacionada aos conceitos de acesso, uso e, consequentemente, de usuário4. Isso porque, nos diversos estudos sobre exclusão digital, os termos são, ou descartados da discussão (como o caso de tipos de uso), como delimitados de formas imprecisas. Esta questão conceitual é levantada por CHEN E WELLMAN (2005) ao enfatizarem que há uma falta de uma definição padrão de quem é um usuário da internet, ou seja, a frequência de uso da mesma e do comprimento da experiência nesta devem ser considerados como dois critérios importantes para a definição de quem são realmente esses usuários. Alguns estudos, generosamente, consideram todos os que já acessaram a rede como um usuário, enquanto outros, de forma mais rigorosa, contam como os usuários somente aqueles que usam a internet pelo menos uma vez por semana. Para tornar essa conceitualização ainda mais confusa, alguns estudos utilizam as famílias, e não indivíduos, como as unidades de análise. Além de dificultar a comparabilidade, isso mascara como membros individuais dentro do agregado familiar usam a internet. Essa proposta teórico-metodológica será desenvolvida, de forma mais complexa, a seguir.

\section{Metodologia}

Este estudo, de acordo com seus objetivos, apresenta característica de pesquisa descritiva e exploratória. Deve-se esclarecer também que esta pesquisa será conduzida por meio de um corte transversal na realidade dos indivíduos estudados. Em se tratando de métodos de pesquisa, optou-se pela abordagem qualitativa na condução desta investigação, a partir do método de pesquisa-ação, para a coleta de informações e da técnica análise de conteúdo, mais especificamente, análise categorial temática, para análise dos dados.

Os estudos de campo qualitativos são aqueles que "privilegiam a análise de microprocessos, através do estudo das ações sociais individuais e grupais,

\footnotetext{
${ }^{2}$ Linguagem, conteúdo e localização são barreiras que se tornam salientes, uma vez acesso básico à Internet está disponível. O inglês, por exemplo, é a língua da Internet; pois, 78 por cento de todos os sites são nesta língua (CHEN e WELLMAN, 2005).

${ }^{3} \mathrm{~A}$ exclusão digital é mais social do que uma ruptura tecnológica. Ter acesso à Internet e ter a capacidade de usá-la efetivamente são duas questões diferentes; ou seja, a questão não é se as pessoas já olharam para um monitor ou colocaram as mãos em um teclado, mas a medida em que eles usam regularmente a internet (CHEN e WELLMAN, 2005).

${ }^{4}$ A frequência de uso da internet e do comprimento da experiência com a mesma são dois critérios importantes para a definição conceitual padrão de quem são os usuários (CHEN e WELLMAN, 2005).
} 
realizando um exame intensivo dos dados, e caracterizada pela heterodoxia no momento da análise" (MARTINS, 2004, p. 289). Dentro desta abordagem, o método de pesquisa-ação foi utilizado. Neste sentido, THIOLLENT (1994) destaca que um dos principais objetivos da pesquisa-ação consiste em alocar junto aos pesquisadores e grupos de participantes os meios para que estes possam responder com maior eficiência aos problemas da situação em que vivem, facilitando assim a busca de soluções aos problemas reais para os quais os procedimentos convencionais têm pouco contribuído.

Deve-se destacar que a adoção desse método de pesquisa está totalmente relacionada com perspectivas ontológicas dos pesquisadores e também aos objetivos do estudo. Isso porque, a avaliação do acesso e, principalmente, uso das tecnologias de informação, neste caso, a computadores desktop e internet, deve ser realizado levando em conta a ampliação dos prazos de coleta de dados e, consequentemente, a interação dos pesquisados com tais tecnologias. Desta forma, a coleta de dados foi realizada, principalmente, por meio da elaboração de diários de campo de todos os encontros 5 com os beneficiários do projeto nas duas instituições parceiras, sendo coletados no período de 2 anos; mas, também, com uma entrevista com o gestor de cada instituição, no momento da confirmação da parceria e do início do projeto.

Finalmente, para organizar e analisar os dados coletados a partir da abordagem qualitativa, utilizou-se o método de análise de conteúdo, mais especificamente, análise categorial temática. A análise de conteúdo pode ser conceituada como um conjunto de técnicas de análise das comunicações, visando, por meio de procedimentos sistemáticos e objetivos de descrição do conteúdo das mensagens, obter indicadores que permitam a busca de conhecimentos relativos às condições de produção/recepção das mensagens (BARDIN, 2004). É importante destacar também que dentre as várias técnicas na análise de conteúdo, que atuam no sentido de promover o alcance e a compreensão dos significados manifestos e latentes no material de comunicação (MINAYO, 2004), esta pesquisa utiliza a técnica de análise categorial. Esta é conduzida por meio da divisão do texto em unidades, ou seja, em categorias, segundo reagrupamentos analógicos. Dentre as várias possibilidades de categorização, a análise temática foi utilizada nesse estudo, dividindo-se, assim, os relatos coletados em unidades de significação (BARDIN, 2004).

\section{Resultados e Discussão}

Esta pesquisa, em relação recíproca com a extensão, objetivou compreender quais são os desafios da inclusão digital de jovens frequentadores de duas entidades do bem-estar do menor no Estado de Minas Gerais. Mais especificamente: analisar como fatores de acesso social (econômicos e culturais) e de infraestrutura de tecnologia de informação dificultam a inclusão digital; identificar comportamentos distintos dos beneficiários do projeto em

\footnotetext{
${ }^{5}$ Cada encontro, com duração de $1 \mathrm{~h} 30 \mathrm{~m}$, era direcionado ao aprendizado de ferramentas de computacionais de escritório, como o pacote BrOffice, e o navegador de internet.
} 
relação aos fatores de uso das tecnologias de informação e comunicação interesse, habilidades e tipos de uso (especificamente, como usa); e propor, a partir dos dados coletados e do referencial teórico utilizado, conceitos e metodologias que abordem o tema de forma mais ampla e complexa6.

Portanto, a partir dos dados coletados, a partir de diários de campo, cinco categorias de análise, ou temas, puderam ser destacados, sendo apresentados a seguir.

\section{Desafios da inclusão digital}

A partir da análise categorial temática dos dados coletados, percebeu-se que a inclusão digital de jovens das instituições objeto de estudo e intervenção, apresentava diversos desafios, que foram abarcados pelos seguintes temas:

Fatores econômicos e culturais, ou seja, de acesso social, como delimitadores persistentes do distanciamento digital;

A falta de infraestrutura física e de TIC adequada, ou seja, laboratório com hardwares, softwares e periféricos em perfeito funcionamento e atualizados, como também a conexão ou banda de internet.

A impossibilidade de acesso e uso contínuo das tecnologias de informação e, consequentemente, das ferramentas aprendidas nos encontros.

Os tipos de usos das tecnologias de informação pelos beneficiários do projeto, nas horas de aula e fora dela.

Os diferentes níveis de aprendizado verificados durante os cursos, com destaque para tipos diferenciados de interesse.

\section{Fatores de acesso social como delimitadores persistentes da exclusão digital}

Pode-se afirmar, seguramente, que a totalidade dos estudos sobre exclusão digital apontam para as diferenças de acesso às tecnologias de informação, a partir de variáveis econômicas e culturais. Para os beneficiários do projeto, isso não é diferente.

Isso porque, estas jovens participam destas entidades por, de alguma forma, serem consideradas em risco social. A grande maioria advém de família de classe social sem acesso a bens generativos de valor, residentes da periferia ou de áreas rurais, sem condições de prover, com dignidade, sua vida. Em uma das entidades pesquisadas, por exemplo, os jovens chegam com idade de dez anos, e ficam morando e recebendo educação formal e profissionalizante até os

${ }^{6}$ O projeto consistia, basicamente, na introdução de conhecimentos de informática básica, a apresentação e aplicação prática do software livre BrOffice (editor de texto, apresentação de slides e planilhas eletrônicas) e noções de internet. 
dezoito anos, quando devem deixar a instituição.

Seus pais ${ }^{7}$, de acordo com as entrevistas com os gestores das instituições, na grande maioria, exercem atividades manuais (algumas delas, rurais), com nenhuma ou pouca utilização de algum tipo de tecnologia, por mais simples que ela seja. O mesmo ocorre em suas residências, ou seja, o acesso a tecnologias de informação, muitas vezes, não é, ao menos, imaginado, visto a grande carência de necessidades outras, como alimentação, a escola básica, acessibilidade e transporte, etc.

Desta forma, a grande maioria dessas jovens, até o início do projeto, não tiveram a oportunidade de ter acesso a um computador desktop, seja em casa ou na escola; muito menos, de usar continuamente estas ferramentas. Ou seja, as instituições parceiras, apesar de apresentarem pequenos laboratórios de informática em sua estrutura, não acrescentavam seu uso nas aulas formais, muito menos, no dia-a-dia dessas jovens.

\section{Estruturas de tecnologia de informação: hardwares, softwares, periféricos e conexão de internet}

Os laboratórios de informática das instituições parceiras do projeto funcionam em pequenas salas. Estas são compostas, ao todo, por 20 computadores, que foram doados, por diversas instituições, às mesmas. Ou seja, atualmente as instituições somente conseguem manter uma estrutura mínima de laboratório de informática, nessas condições. Isso, apesar de ser um grande benefício para a instituição, não contempla satisfatoriamente as necessidades de acesso e uso computacional dos alunos envolvidos com a mesma; muitas vezes, porque são em número insuficiente, devido ao número de alunos frequentes nas instituições, e estão em processo de vida útil avançada, desatualizada e, consequentemente, em precárias condições de funcionamento.

Analisando os diários de campo, pode-se perceber como laboratórios de informática, nestas condições de acesso, prejudicam a inclusão digital dos alunos do curso e das instituições como um todo. Isso porque, como visto anteriormente, a maioria destas jovens vêm de realidades econômicas e culturais muito precárias e, um de seus únicos locais de acesso e uso, ocorre nas entidades durante 0 projeto. Esses problemas estão relacionados principalmente com defeitos em hardwares, seguidos de periféricos e softwares (que, em sua totalidade, são desatualizados).

Alguns relatos presentes nos diários de campo deixam claro esses desafios:

\footnotetext{
${ }^{7}$ De acordo com a tipologia de classificação de Santos (2005) esses indivíduos podem ser categorizados, em relação ao trabalho, em trabalhadores manuais não qualificados e trabalhadores agrícolas. Ver: SANTOS, J. A. F. 2005. Uma classificação socioeconômica para o Brasil. Revista Brasileira de Ciências Sociais, v. 20, no 58, junho.
} 
(Instituição I) Notei também que dois computadores não reconheceram meu pendrive, mas estou trabalhando para instalar o driver dele nestas máquinas.

(Instituição II) Permaneci o período da aula toda realizando as manutenções que ainda são necessárias para o laboratório. Na segunda-feira terminarei as manutenções antes mesmo das aulas começarem.

Os principais desafios à inclusão digital encontrados aqui apresentam-se a partir das seguintes categorias: número reduzido de computadores em precárias condições de acesso e funcionamento, em termos de hardwares, softwares e periféricos, ou seja, fatores relativos à qualidade da tecnologia. Esta, por sua vez, prejudicava o número de alunos que poderiam fazer o curso em cada turma e, também, o acesso contínuo destes alunos a tais tecnologias (hábito não institucionalizado e permitido formalmente pelas instituições parceiras); fatores relativos ao ambiente, privacidade e facilidade de utilização. Também, gerava a redução no tempo de duração do curso de cada turma que, frequentemente, tinha que ser dedicado à manutenção de hardwares, softwares e do sistema operacional presente nos computadores.

SELWYN (2004) já destacava estes desafios quando estudou a inclusão digital. De acordo com o mesmo, problemas de custos, a qualidade da tecnologia e do ambiente no qual é utilizada, bem como, privacidade e a facilidade de utilização devem ser considerados cruciais na mediação do acesso às tecnologias de informação e comunicação. Portanto, percebe-se claramente que, apesar das pesquisas anteriores sobre a exclusão digital destacarem, como variáveis de análise, não somente o acesso às tecnologias, mas também, os tipos de uso, as diferenças ou discrepâncias de acesso no que tange à qualidade, manutenção e atualidade dos equipamentos, estes, continuam sendo, de acordo com o estudo em questão, variáveis de segregação, distanciamento e, consequentemente, da divisão digital8.

Outra questão importante levantada neste artigo diz respeito ao acesso descontínuo das tecnologias de informação e comunicação. Isso porque, a maioria dos beneficiários do projeto não possui computador em casa e, aqueles que têm, não possuem acesso à internet e, também, muitas vezes, somente conseguem acesso aos computadores nos dias de aula, ou seja, duas vezes por semana (devido ao número reduzido e precário de computadores das instituições parceiras e a não institucionalização ou permissão formal de uso contínuo dos equipamentos pelas mesma).

Refletindo em termos da desigualdade relativa, não há como desconsiderar o acesso desigual às tecnologias de informação e comunicação, por jovens que apresentam capital econômico e cultural distintos (principalmente na escola e em casa). Ou seja, a desigualdade de acesso, apesar do avanço conceitual dos estudos sobre desigualdade digital, continua sendo variável primordial de análise nas pesquisas sobre o tema.

\footnotetext{
${ }^{8}$ É importante destacar que esta afirmação não apresenta a pretensão de ser generalizada, a partir de um estudo qualitativo.
} 
Esse acesso não contínuo às TIC e, consequentemente, a não utilização frequente dos conhecimentos desenvolvidos durante os módulos do curso, faziam que os alunos, de uma semana para a outra, esquecessem muitas funcionalidades das ferramentas computacionais. Assim, a realização de constantes revisões dos conteúdos anteriores tornou-se uma necessidade constante. projeto.

Alguns relatos dos diários analisados demonstraram esse desafio para o

(Instituição I) Como eu esperava, muitos alunos esqueceram seus logins e senhas e eu novamente informei a importância de anotar seus dados para realizar os acessos. Perdemos 30 minutos de aula para recadastramento de email.

(Instituição II) Muitos alunos da turma têm pouco contato com o computador, apresentando dificuldades em até usar o mouse.

A conexão de internet também pôde ser considerada um grande desafio para a inclusão digital destes jovens. Isso porque, devido ao baixo pacote de conexão, quando esta era utilizada conjuntamente e, sua banda de internet dividida entre os computadores conectados à rede, o acesso às informações tornava-se praticamente impossível. Isso devido à divisão da banda de conexão e às condições precárias dos computadores. Nestes momentos, devido a esse gap nas atividades desenvolvidas no dia, o comportamento dos alunos tornavase disperso, sendo a construção dos conteúdos descontinuado e, consequentemente, prejudicado (a partir, mais uma vez, de precariedade de acesso). É importante relembrar, mais uma vez, que o acesso o uso destes alunos às tecnologias de informação, ocorria, na maioria das vezes, somente na instituição de apoio.

Alguns relatos demostram muito bem o surgimento desta categoria como uma grande barreira tecnológica para a inclusão digital, visto que, a construção desse conhecimento era, mais uma vez, prejudicado.

(Instituição I) Hoje os alunos ficaram por conta das pesquisas feitas na internet. Esses tipos de pesquisas são complicados de serem feitos, pois a internet fica dividida para muitos computadores, e a conexão diminui drasticamente.

(Instituição II) O supervisor falou comigo hoje sobre a internet e disse que a instituição, no momento, está sem condições de comprar o equipamento necessário para realizar a conexão de todos os computadores.

Uma importante questão levantada no referencial teórico e que deve ser retomada aqui é a delimitação conceitual do termo usuário. Isso porque, como enfatizado por CHEN E WELLMAN (2005), nos diversos estudos sobre exclusão digital, há uma falta de uma definição padrão de quem é um usuário da internet. Consequentemente, como proposta conceitual, este estudo delimita usuário como um indivíduo que acessa e usa alguma tecnologia de informação e 
comunicação9 diariamente. Primeiramente, quando se fala em tecnologias de informação e comunicação, reconhece-se mais que o acesso e o uso da internet, acrescentando, também, o uso de softwares aplicativos, visto que, o usuário, indivíduo digitalmente incluso, deve saber não somente utilizar a internet, mas também, softwares aplicativos, visando solucionar problemas do seu dia-a-dia. Já a questão do uso diário, de imediato, pode soar excessivo. Mas, levando-se em conta, de forma ideal, o conceito de sociedade digital e, consequentemente, da ampliação e uso das tecnologias de informação e comunicação na vida cotidiana, seja na rua, em casa, na escola, na universidade, no trabalho, não há como conceituar o usuário de tecnologias de informação de outra maneira; ou seja, indivíduos que acessam e usam, diariamente, os recursos tecnológicos como ferramentas para interagir no mundo digital e serem capazes, não somente de saber encontrar a informação, mas também processá-la, qualificála e torná-la útil para seu dia a dia.

Assim, a partir dessa delimitação conceitual, acredita-se que haverá uma ampliação do número de indivíduos excluídos digitalmente nas pesquisas, visto que, a polarização acesso/não acesso e o acesso a tecnologias de informação e comunicação, de forma esporádica, não deve mais abarcar conceitualmente o usuário.

Também, buscou-se entender quais os tipos de usos, ou seja, o que os alunos faziam ou solicitavam autorização para fazer nas aulas, além do delimitado pelos monitores das turmas. Assim, há o destaque, em todas as turmas, do uso da internet, quase que exclusivamente, das redes sociais, e do acesso a jogos instalados nos computadores, durante a apresentação dos conteúdos teóricos. Isso será apresentado e discutido a seguir.

\section{Tipos de uso: internet e jogos}

O acesso às redes sociais e/ou a jogos, com ou sem a autorização dos monitores, eram uma constante. $O$ motivo pode estar relacionado, primeiramente, às instituições parceiras, ou seja, além das condições precárias (tanto de hardware, software e internet), como delimitado anteriormente, os alunos somente podiam usar os computadores das instituições, salvo algumas exceções, durante as aulas vinculadas ao projeto. Outra questão relacionada é que a instituição se torna o único local de acesso para os estudantes, visto que a maioria não tem computador e internet em casa, ou seja, o laboratório da instituição parceira é uma das poucas oportunidades de aprender e aperfeiçoar seu conhecimento adquirido com as aulas, juntamente com seus interesses no mundo tecnológico e virtual.

Alguns relatos deixam claro esse comportamento durante os encontros.

(Instituição I) Um dos maiores problemas que enfrentei foi a gerência do uso da internet, principalmente de sites de relacionamento.

\footnotetext{
${ }^{9}$ Seja ela computador desktop, notebook, smartfone, tablet, smart TV, etc.
} 
(Instituição II) Para tentar mudar isso permiti pausas para jogos (que eram acessados constantemente) entre cada uma das atividades de digitação para tonar o modulo menos cansativo, visto que ele exige esforço das mãos e coordenação. Mas isso fez com que alguns alunos tentassem correr ainda mais com atividade sem prestar atenção com o aprendizado para terminar rápido e jogar.

Aqui, torna-se importante retomar a discussão de LIVINGSTONE $E$ HELSPER (2007), quando afirmam em seu estudo que jovens que usam a internet com mais frequência, tem mais oportunidades online. Inversamente, os que passaram a ter acesso mais recentemente, e que não têm confiança nas suas habilidades, usam a internet de forma mais conservadora, ocupando menos oportunidades. A primeira afirmativa dos autores é, de forma fática, facilmente perceptível, pois retrata a estratificação do acesso às tecnologias de informação e comunicação e ao conhecimento, seja ele científico ou não. Já a segunda afirmação delimitada pelos autores torna-se não tão clara quanto à primeira. Isso porque, ao utilizar a categoria "usam a internet de forma mais conservadora", os autores deixam dúvidas sobre qual tipo de ação é adotada por esses indivíduos (apesar de, claramente, ocuparem menos oportunidades).

Já as conclusões de PETER E VALKENBURG (2006) destacam que adolescentes com melhores níveis socioeconômicos e cognitivos usam a internet, mais frequentemente, para buscar informações, e menos, para buscar entretenimento, em relação a seus pares menos favorecidos, torna-se mais compatível com os resultados alcançados no estudo hora desenvolvido. Isso porque, apesar de não realizar um estudo comparativo do uso da internet por adolescentes de níveis socioeconômicos distintos, percebeu-se que a maioria dos jovens beneficiários do projeto consideravam as tecnologias de informação e comunicação, neste caso, o computador desktop com conexão de internet, como entretenimento (salvo raras exceções), pois o acesso contínuo à internet e a jogos, com ou sem autorização dos monitores, eram constantemente repetidos. Todavia, deve-se esclarecer que esse comportamento pode estar repercutindo o pouco acesso que esses jovens têm, semanalmente, às tecnologias de informação e comunicação. Faz-se essa afirmação com grande tranquilidade, pois, durante o processo de escolha dos alunos que participariam das aulas (devido à grande demanda e o número reduzido de computadores), a maioria afirmou que seu interesse no curso estava relacionado a ter mais chances de conseguir um bom emprego (mas, esse também pode ser um discurso enfatizado pelas instituições parceiras, visto que, eram direcionadas, como dito, a jovens em risco social).

Também, buscou-se perceber se os participantes apresentavam diferentes níveis de interesse e aprendizado. Isso será discutido e analisado no próximo tópico.

\section{Diferentes tipos de interesse e aprendizado}

Como apresentado anteriormente, a maior parte dos alunos dos cursos apresentavam dificuldades de aprendizado das ferramentas de tecnologia de 
informação e comunicação apresentadas, visto que tinham contato com estas tecnologias quase que exclusivamente nas instituições parceiras e que, também, apresentam um histórico de acesso e uso restrito das mesmas.

Todavia, alguns alunos do curso, de acordo com os relatos coletas nos diários de campo, apresentavam, nesses momentos, interesses e, consequentemente, aprendizados diferenciados. No que se refere aos tipos de interesses, pode-se perceber que alguns alunos apresentavam comportamento diferenciado na busca de informações extras do que fora apresentado em sala. Alguns desses acessos às tecnologias de informação e comunicação, em busca destas informações, ocorriam nos laboratórios de informática das instituições parceiras; outros, não (apesar dos dados da pesquisa não possibilitarem saber onde ocorreu esse acesso).

(Instituição I) O aluno M. T., que nunca tinha mexido em computador, recebeu uma crítica construtiva na aula passada sobre não saber de algumas coisas do conteúdo de seus slides e me trouxe uma pesquisa com cada assunto que citei. Realmente impressionante, aquele menino é sensacional.

(Instituição II) J. é um menino divertido, parece conhecer bastante coisa sobre computação e até mesmo me mostrou como criar uma pasta invisível no computador, foi bom para ter maior reconhecimento do professor para com o aluno.

Uma questão importante que deve ser levantada aqui diz respeito, mais uma vez, à delimitação do usuário; mas, considerando aqui os aspectos metodológicos, concernentes, especificamente, à coleta de dados a serem priorizadas nos estudos de exclusão digital, devido à complexidade do fenômeno. Ou seja, baseando no apresentado e discutido anteriormente, de acordo com CHEN E WELLMAN (2005), alguns estudos utilizam, como unidade de análise, as famílias, e não indivíduos.

Essa afirmação, de certa forma, pode ser corroborada a partir da análise dos dados acima; apesar dos estudos serem de viés qualitativo (com amostragem não probabilística) e não aplicar um questionário estruturado (visando coletar informações sobre variáveis sociodemográficas dos beneficiários do projeto) pode-se afirmar que eles pertencem a uma mesma categoria de análise, isto é, jovens com pouco ou nenhum acesso a bens generativos de valor e em risco social (isso porque esses critérios são utilizados durante os processos de seleção destas jovens para adentrarem as instituições). Mas, apesar disso, apresentam interesses e aprendizados diferenciados, inviabilizando, assim, considerar agregados familiares e não o indivíduo enquanto unidade de análise. Outros relatos, sobre os distintos níveis de aprendizado ajudam a esclarecer e direcionar o exposto.

(Instituição II) Hoje N. ajudou três alunos a fazerem e-mail, e foi muito importante para mim a ajuda dele. Além disso, como havia parado de chover, na aula eu enviei um e-mail para a turma 
anexando uma imagem de um texto educativo para eles treinarem no Editor de Textos, e N. enviou e-mail anexado para esses alunos que fizeram o e-mail depois. Gostei muito.

(Instituição I) Para os alunos que fizeram a aula de digitação, a digitação fluiu muito melhor, ressaltando M.T., que nunca havia mexido em um computador e foi 0 aluno que teve o melhor desempenho. Realmente M. T. é um menino ótimo, aprende tudo que ensino e deu um show nos outros alunos.

Portanto, longe de objetivar desqualificar os estudos quantitativos com amostragem probabilística, esta pesquisa, a partir da análise de seus dados e do referencial teórico utilizado, pretende sugerir a triangulação de métodos em estudos sobre a desigualdade digital. Dessa forma, sugere-se que os estudos direcionados ao tema adotem metodologias de pesquisas quantitativas e qualitativas, visando abordar, de forma mais complexa e metodologicamente válida, o fenômeno.

Isso porque, como apresentado, os estudos sobre exclusão digital devem abordar não somente questões sociodemográficas e o acesso ou não, mas também, o histórico desse acesso em um ambiente social e os tipos de acesso e uso das tecnologias de informação e comunicação (seja, em casa, na escola, na universidade ou no trabalho). Assim, os métodos de pesquisa-ação, grupo de foco, observação participante, história de vida e história oral seriam um suporte essencial aos estudos que objetivam analisar o fenômeno da exclusão digital, não somente a partir de uma perspectiva macro, mas, em seus diversos aspectos micro, tornando-os mais válidos e confiáveis.

\section{Considerações finais}

Esta pesquisa, em relação recíproca com a extensão, objetivou compreender quais são os desafios da inclusão digital de jovens frequentadores de duas entidades do bem-estar do menor no Estado de Minas Gerais. Neste sentido, destaca-se, inicialmente, que os fatores de acesso social (econômicos e culturais) e de infraestrutura de tecnologia de informação permanecem persistentes no que se refere ao distanciamento gerado em jovens em risco social com pouco ou nenhum conhecimento em tecnologias de informação e comunicação. Isso foi observado, inicialmente, a partir do acesso restrito destas jovens no uso dessas tecnologias em casa e na escola. Como observou-se, essas crianças pertencem a categorias sociais com acesso restrito a bens gerativos de valor, que tem seus diversos direitos historicamente cerceados, inclusive os de acesso à educação, à informação e ao conhecimento.

Paralelamente a isso, observou-se também que as estruturas de tecnologias de informação e comunicação disponibilizadas a elas pelas instituições eram deficientes em seus diversos componentes, ou seja, hardwares, softwares, periféricos e conexão de internet. Esses determinantes de acesso, no que tange à qualidade dos equipamentos utilizados, foram uma 
grande barreira à inclusão digital desses indivíduos; isso, no campo teórico, também gerou implicações, ao delimitar-se, conceitualmente, o usuário de tecnologias de informação e comunicação.

Portanto, não há como conceituar o usuário de tecnologias de informação de outra maneira; ou seja, indivíduos que acessam e usam, diariamente, os recursos tecnológicos como ferramentas para interagir no mundo digital e serem capazes não somente saber encontrar a informação, mas também processá-la, qualificá-la e torná-la útil para seu uso diário em sua vida cotidiana.

Outra questão delimitada pela pesquisa diz respeito aos comportamentos distintos dos beneficiários do projeto em relação aos fatores de uso das tecnologias de informação e comunicação - interesse, habilidade e tipos de uso (especificamente, como usa). Como se pôde observar, a maior parte dos beneficiários do projeto apresentavam grandes dificuldades diárias para entendimento e uso das ferramentas tecnológicas disponibilizadas em determinado momento, fato esse que foi constantemente relatado pelos bolsistas do projeto em seus diários de campo. $\mathrm{E}$, somente um número reduzido de alunos, com alguma experiência anterior com as tecnologias de informação e comunicação ou não, apresentavam, ao mesmo tempo, um maior interesse em buscar informações e, também, um nível de aprendizado mais desenvolvido, demostrando maior interesse e habilidade com as ferramentas disponibilizadas. Mas, o ponto central aqui é demonstrar que o acesso e uso esporádico de jovens, com pouco ou nenhum conhecimento de tecnologias de informação e comunicação, gera um efeito de curto prazo e paliativo, visto que a grande maioria dos beneficiários do projeto esqueciam, de uma semana para outra, o conteúdo apresentado pelos monitores; e, após o término do curso, de duração de três meses, não persiste a dúvida de que a tentativa de incluí-los digitalmente tem grandes chances de fracassar; devido, principalmente, a fatores de acesso social. Portanto, a impossibilidade de acesso e uso contínuo desses bens gerativos de valor são ainda variáveis que devem ser consideradas nas análises sobre o tema.

Também foi levantado no trabalho dados referentes aos tipos de uso dessas tecnologias pelos beneficiários do projeto. Estes dados mostram, como apresentado, que, no que tange aos tipos de uso, os alunos ainda percebem as mesmas como um entretenimento (apesar do discurso de fazer o curso para conseguir trabalho), direcionando sempre seus interesses principais de uso para as redes sociais e jogos instalados nos computadores. Isso porque, como dito, a maioria dos alunos não tem computador com conexão de internet em casa, conseguindo acessá-las somente nas instituições durante as aulas de computação e, esporadicamente, em pequenos momentos na semana. Levantase essa afirmação visando deixar em dúvida e, convicto da realização de pesquisas futuras que, estes indivíduos poderiam ter um comportamento distinto, caso tivessem acesso diário a tecnologias de qualidade (em casa e na escola); ou seja, acessar e utilizar, quando em contato com as mesmas, não somente aplicativos e páginas que visam o entretenimento, pois, mesmo dentro 
das redes sociais, podem-se criar diversas possibilidades, envolvendo negócios, artes, cultura, participação política etc. Mas, também deve-se destacar que, um pequeno número de alunos apresentou tipos de uso distintos, ao buscar informações extraclasse ou dedicando-se mais às atividades direcionadas ao aprendizado das ferramentas computacionais; apresentando, também, níveis mais elevados de aprendizado em relação à grande maioria das turmas (não descartando, é claro, o interesse em redes sociais e jogos).

A partir do apresentado anteriormente, há um duplo caminho a ser percorrido, quando se tem em consideração ações e pesquisas envolvendo o tema da exclusão digital. Primeiramente, a necessidade de ampliação do acesso às tecnologias de informação torna-se uma prioridade, seja por meio de projetos do governo federal, estadual ou municipal, parcerias público/privadas, incentivos fiscais para a criação de condições de compra favorável para famílias que não têm acesso a esses bens. Portanto, ações de inclusão digital que visem capacitar pessoas em ferramentas computacionais, neste caso, jovens de famílias com acesso precário a bens gerativos de valor, necessitam caminhar conjuntamente com projetos que visem a ampliação do acesso a tais tecnologias (pois, caso contrário, serão um mero paliativo de curto prazo). Segundo, os estudos devem buscar adotar, em seus procedimentos metodológicos, abordagens qualitativas, a partir dos métodos de história oral, história de vida, observação participante ou não-participante, visando elucidar questões de acesso e uso social, tipos e habilidades de uso, qualidade do equipamento usado, diferentes tipos de interesse etc. O destaque para os métodos de pesquisa qualitativos não tem a pretensão de desacreditar e ou desestimular 0 uso de metodologias quantitativas com amostragem probabilística e aplicação de survey nos estudos sobre inclusão digital; mas sim alertar para, primeiro, a complementaridade dos métodos, e também para a necessidade de determinadas pesquisas sobre o tema, devido às peculiaridades do seu problema e objetivo de pesquisa, adotarem métodos qualitativos em suas buscas e análises de dados.

\section{Referências bibliográficas}

BARDIN, L. 2004. Análise de conteúdo. $3^{a}$ ed. Portugal: Edições 70.

BILLS, David B. 2004. The Sociology of Education and Work. Oxford, Blackwell.

BROWN, David K. 2001. The Social Sources of Educacional Credentialism: status, cultures, labor markets and organizations. Sociology of Education, Extra Issue, 19-34.

CHEN, W.; WELLMAN, B. 2005. Minding the Cyber-gap: the Internet and Social Inequality. In: ROMERO, M.; MARGOLIS, E. The Blackwell Companion to Social Inequalities. Blackwell Publishing.

COLLINS, R. 1979. The Credential Society: An Historical Sociology of Education and Stratification. New York: Academic Press. 
CYSNE, R.; ALVES, J. E. D.; CÔRTES, S. da C. 2007. O desafio da exclusão digital: uma análise multivariada com base na Pnad 2005, Brasília, Inclusão Social, v. 2, n. 2, pp. 46-56, abril/setembro.

ERICKSON, B. H. 1997. Social networks and history: a review essay. Historical Methods, v. 30, n. 3, pp. 149-57, summer.

FERNANDEZ, O. S. N. 2010. Do desenvolvimentismo à inclusão social. Inclusão Social, Brasília, DF, v. 3, n. 2, pp.119-128, janeiro/junho.

GOODE, J. 2010. The digital identity divide: how technology knowledge impacts college students. New Media \& Society, USA, v. 12, n. 3, pp.497-513, february.

HARGITTAI, E. 2010. Digital na(t)ives? Variation in internet skills and use among members of te "net generation". Sociological Inquiry, v. 80, n. 1, pp. 92-113, February.

JACOBI, P. 2006. Public and private responses to social exclusion among youth in São Paulo. The ANNALS of the American Academy of Political and Social Science, v. 606, pp. $216-230$, July.

JAMES, J. 2003. Free software and the digital divide: opportunities and constraints for developing countries. Journal of Information Science, v. 29, n. 1, pp. 25-33, February.

LIVINGSTONE, S., HELSPER, E. 2007. Gradations in digital inclusion: children, young people and the digital divide. New Media Society. Los Angeles, London, New Delhi and Singapore, v. 9, n. 4, pp. 671 - 696, November.

MASSEY, D. 2007. How Stratification Works. In:

Categorically Unequal. New York, Russell Sage Foundation.

MATTOS, F. A. M; CHAGAS, G. J. N. 2008. Desafios para a inclusão digital no Brasil. Perspectiva em Ciência da Informação, v.13, n.1, pp. 67-94, janeiro/abril.

RIDGEWAY, Cecília. 2013. Why status matters for inequality. American Sociological Review, v. 79, n. 1, pp. 1-16, december.

SELWYN, N. 2004. Reconsidering political and popular understandings of the digital divide. New Media Society, v. 6, n. 3, pp. 341-362, summer.

SHELLEY, M., THRANE, L., SHULMAN, S., LANG, E., BEISSER, S., LARSON, T., MUTITI, J. 2004. Digital citizenship: parameters of the digital divide. Social Science Computer Review, v. 22, n. 2, pp. 256 - 269, May.

SILVEIRA, S. A. 2005. Inclusão digital, software livre e globalização contra hegemônica. Parcerias Estratégicas, n. 20, pp. 421-446, junho. 
TAKAHASHI, T. 2005. Inclusão social e TICs. Inclusão Social, Brasília, v. 1, n. 1, pp. 56-59, outubro/março.

TESTA, A. F. 2007. Cidadania digital e competitividade. Inclusão Social, Brasília, v. 2, n. 1, pp. 67-72, março.

TILLY, C. 1999. Durable inequality. In: PHYLLIS, M. A nation divided. United States: Cornell University Press.

TILLY, C. 1999. Historical perspectives on inequality. In: ROMERO, M.; MARGOLIS, E. The blachwell companion to social inequalities. United Kingdom: Blackwell Publishing Ltda.

WARSCHAUER, M. 2003. Technology and social inclusion: rethinking the digital divide. Massachusetts: MIT Press.

WILSON, K. R.; WALLIN, J. S.; REISER, C. 2003. Social stratification and the digital divide. Social Science Computer Review, v. 21 n. 2, pp. 133-143, summer.

WRIGHT, E. O. 1969. Logics of class analysis. In: LAUREAU, A.; CONLEY, D. Social class: how does it work. United States: The Russell Sage Foundation.

YOUNG, R. 2006. Inclusão digital e as metas do milênio. Inclusão Social, Brasília, v. 1, n. 2, pp. 96-99, abril/setembro. 